\title{
O DOCUMENTO SOBRE A TEOLOGIA DA COMISSÃO TEOLÓGICA INTERNACIONAL - CTI
}

\author{
Document about Theology of International \\ Theological Commission - CTI
}

\section{Geraldo Luiz Borges Hackmann}

O documento da Comissão Teológica Internacional, intitulado Teologia hoje: perspectivas, princípios e critérios, publicado em 2011, foi preparado durante dois quinquênios por duas subcomissões diferentes, visto a primeira subcomissão não ter conseguido completar o trabalho. As discussões em torno do tema do estatuto da Teologia tiveram início 2004 e foram concluídos e aprovados de forma específica na sessão plenária de 29 de novembro de 2011. O documento, então, foi submetido ao Cardeal Willian Levada, prefeito da Congregação para a doutrina da Fé, que autorizou a sua publicação.

A origem desse documento se deve ao pedido explícito da Congregação para a Doutrina da Fé à Comissão Teológica Internacional para refletir sobre o estatuto da Teologia e seu método diante da constatação de que a Congregação, no desempenho de sua tarefa, que a levava a dialogar com diversos teólogos, estava encontrando dificuldades quanto ao método teológico e à concepção do fazer teologia, o que gerava falta de um ponto de referência para os diálogos com os teólogos chamados para discutir sobre seus escritos e seus pontos de vista da tradição teológica. Assim, sentia-se a necessidade de certa unidade em torno da Teologia, que chegasse a um "discurso comum", sem cair na "uniformidade" ou num "estilo comum" (n. 2).

Sendo assim, a Comissão Teológica Internacional iniciou sua tarefa, que foi concluída com a publicação desse Documento, que se

\begin{tabular}{|l|l|l|l|l|l|}
\hline Teocomunicação & Porto Alegre & v. 44 & n. 1 & p. 138-150 & jan.-abr. 2014 \\
\hline
\end{tabular}


situa ao lado de outros documentos publicados anteriormente, como A unidade da fé e o pluralismo teológico (1972); Magistério e a Teologia (1975); e A interpretação do Dogma (1990). O objetivo do Documento é claro:

O presente texto procura identificar os traços familiares distintos da teologia católica. Consideram-se as perspectivas e os princípios básicos que caracterizam a teologia católica, e oferecem critérios pelos quais teologias diversas e múltiplas possam ser reconhecidas como autenticamente católicas e como participantes da missão da Igreja Católica, que é a de proclamar a Boa Nova às pessoas de todas as nações, tribos, povos e línguas (cf. Mt 28,18-20; Apoc 7,9), e, permitindo-lhes ouvir a voz do único Senhor, reuni-los todos em um só rebanho e um só pastor (cf. Jo 10,16) (n. 3).

Na Introdução, fazem-se três constatações:

- A primeira constatação diz respeito ao florescer da reflexão teológica, acontecido nos anos sucessivos ao Vaticano II:

Os anos sucessivos ao Concílio Vaticano II foram extremamente produtivos para a teologia católica. Surgiram novas vozes teológicas, especialmente de leigos e de mulheres; teologias provenientes de novos contextos culturais, particularmente da América Latina, África e Ásia; novos temas para a reflexão, como paz, justiça, libertação, ecologia e bioética; aprofundamentos de temas já tratados, graças à renovação dos estudos bíblicos, litúrgicos, patrísticos e medievais; e novos espaços para a reflexão, como o diálogo ecumênico, inter-religioso e intercultural. Esses desenvolvimentos foram fundamentalmente positivos (n. 1).

- A segunda constatação refere-se a uma fragmentação da teologia ocorrida após este progresso teológico acontecido no período posterior ao término do Vaticano II:

No entanto, neste mesmo período, também aconteceu uma fragmentação da teologia, que, no diálogo acima referido, sempre se encontra diante do desafio de manter a sua verdadeira identidade. A questão surge, por conseguinte, sobre o que caracteriza a teologia católica e dá a ela, em e através de suas múltiplas formas, um claro sentido de identidade em seu confronto com o mundo de hoje (n. 1). 
- A terceira constatação afirma a necessidade de um discurso comum para poder comunicar a mensagem de Cristo ao mundo:

Em certa medida, a Igreja necessita claramente de um discurso comum se quiser comunicar a mensagem única de Cristo ao mundo, tanto teológica quanto pastoral. Por essa razão, pode-se falar legitimamente da necessidade de certa unidade da Téologia. Todavia, aqui a unidade necessita ser bem compreendida, a fim de que não seja confundida com uniformidade ou com um único estilo. A unidade da teologia, como a da Igreja, assim como é professada no Creio, deve ser estreitamente correlacionada com a ideia de catolicidade, e também com a de santidade e apostolicidade (n. 2).

\section{Perspectivas}

As perspectivas encontram-se nos capítulos primeiro e terceiro do Documento, intitulados, respectivamente, A escuta da Palavra de Deus e Dando conta da verdade de Deus. Essa é a grande perspectiva da Teologia, enquanto determina a sua razão de ser. Ela é assim justiicada:

A teologia, em todas as suas diversas tradições, disciplinas e métodos, está radicada no ato fundamental de ouvir na fé a Palavra de Deus revelada, o próprio Cristo. A escuta da Palavra de Deus é o princípio definitivo da Teologia Católica, que leva à compreensão, ao anúncio e à formação da comunidade cristã: 'a Igreja é edificada sobre a Palavra de Deus, ela nasce e vive por essa palavra' (Verbum Domini, n. 3) (n. 4).

Sendo assim, são apontadas seis perspectivas para a Teologia, abordadas a seguir, de acordo com o texto do Documento:

A primeira perspectiva é o primado da Palavra de Deus

Tal primado provém de que "o evangelho de Deus é fundamentalmente testemunhado pela Sagrada Escritura do Antigo e Novo Testamento (cf. Dei Verbum, nn. 7, 11 e 16), que é "inspirada por Deus e consignada por escrito de uma vez para sempre" e, por isso, "comunicam imutavelmente a palavra do próprio Deus e fazem ressoar através das palavras dos Profetas e Apóstolos a voz do Espírito Santo" (Dei Verbum, n. 21). A transmissão fiel da Palavra de 
Deus é feita pela Tradição, "testemunhada no cânon das Escrituras por meio dos profetas e apóstolos e na leiturgia (liturgia), martyria (testemunho) e diakonia (serviço) da Igreja". Por essa razão, a "Igreja venera extremamente as Escrituras, mas é importante reconhecer que a fé cristã não é uma 'religião do livro'; cristianismo é a 'religião da Palavra de Deus', não de 'uma palavra escrita e muda, mas do Verbo encarnado e vivo'. A relação entre a Escritura e a Tradição está enraizada na verdade que Deus revela na sua Palavra para nossa salvação" (nn. 7 e 8).

A segunda perspectiva é a fé como resposta à Palavra de Deus:

a) “A fé é tanto ato de crença ou de confiança quanto também do que é crido ou confessado, ou seja, fides qua e fides quae, respectivamente. Ambos os aspectos operam juntos inseparavelmente, uma vez que a confiança é a adesão a uma mensagem com um conteúdo inteligível, e a confissão não pode ser reduzida a simples palavras sem conteúdo, mas deve vir do coração".

b) "A fé é, ao mesmo tempo, uma realidade profundamente pessoal e eclesial. Ao professar a própria fé, os cristãos dizem tanto "eu creio" quanto "nós cremos". A fé é professada na koinonia do Espírito Santo (cf. 2Cor 13,13), que une todos os cristãos a Deus e entre si (cf. $1 J_{o} 1,1-3$ ), e atinge a sua expressão máxima na Eucaristia (cf. 1Cor 10,16-17)".

c) "As profissões de fé se desenvolveram no seio da comunidade dos fiéis desde os tempos mais antigos. Todos os cristãos são chamados a dar testemunho pessoal da própria fé, mas os Credos permitem à Igreja de professar a sua fé. Essa profissão de fé corresponde ao ensinamento dos apóstolos, à Boa Nova, na qual a Igreja permanece firme e pela qual é salva (cf. 1Cor 15,1-11)".

d) "O Novo Testamento mostra abundantemente que, desde os primórdios da Igreja, algumas pessoas propuseram uma interpretação "herética" da fé comum, uma interpretação contrária à Tradição Apostólica. (...) A heresia, portanto, não só distorce o Evangelho, como também prejudica a comunhão eclesial. (...) Quem é culpado de tal obstinação contra o ensinamento da Igreja deve substituir seu próprio julgamento 
pela obediência à palavra de Deus (o motivo formal da fé), a fides qua. A heresia serve como um lembrete de que a comunhão da Igreja só pode ser assegurada se fundada na base da fé católica em sua integridade, e impele a Igreja a uma busca cada vez mais profunda da verdade na comunhão" (nn. 13 e 14).

A terceira perspectiva é a Teologia entendida como compreensão da fé:

a) A Teologia brota da fé e, ao mesmo tempo, a alimenta. "Este é o caminho que conduz à compreensão da fé (intellectus fidei). (...) Esse trabalho de inteligência da fé, por sua vez, contribui para alimentar a fé e fazê-la crescer. Assim é que "fé e razão são como duas asas pelas quais o espírito humano se eleva para a contemplação da verdade" (Introdução à Fides et Ratio)" (n. 17).

b) "O intellectus fidei assume várias formas na vida da Igreja e na comunidade dos crentes, de acordo com os diferentes dons dos fiéis (lectio divina, meditação, pregação, teologia como ciência, etc.). Torna-se teologia, no sentido estrito, quando o crente se compromete a apresentar o conteúdo do mistério cristão de uma forma racional e científica. A teologia é, portanto, scientia Dei na medida em que é uma participação racional no conhecimento de que Deus tem de si mesmo e de todas as coisas" (n. 18).

A quarta perspectiva é a relação entre a verdade de Deus e a racionalidade da teologia

Ela aponta para a natureza científica da teologia, pois "a verdade de Deus, acolhida na fé, encontra a razão humana” (n. 62). Daí, é necessário o diálogo entre fé e razão, entre filosofia e teologia. Tal necessidade atinge tanto a fé quanto a ciência (n. 64), além de nunca ter existido, por parte da teologia (n. 64-69), rejeição à ciência, apesar da crítica radical feita pelo iluminismo à fé (n. 70). Contudo, há um novo desafio posto pela crise pós-moderna da própria razão clássica, diante da ambiguidade do conceito de "verdade" (n. 71). O Papa João Paulo II, na Fides et Ratio 66, rejeita tanto o fideísmo quanto o ceticismo filosófico (n. 72). É como afirma o Documento: 
Assim, a verdade revelada de Deus ao mesmo tempo exige e estimula a razão do crente. Por um lado, a verdade da Palavra de Deus deve ser examinada e investigada pelo crente - assim que tem início o intellectus fidei, a forma assumida aqui na terra pelo desejo do crente de ver a Deus. (...) Pelo uso da razão, o crente apreende as conexões profundas entre as diversas etapas da história da salvação e, também, entre os diversos mistérios da fé, que se iluminam reciprocamente. Por outro lado, a fé estimula a própria razão em si e alarga os seus limites. A razão é estimulada a explorar caminhos que, sozinha, não teria sequer suspeita que pudesse percorrer" (n. 63).

A quinta perspectiva é a unidade da Teologia em relação com à pluralidade dos métodos e disciplinas:

O Documento entende que há uma teologia: “A teologia católica, fundamentalmente entendida com Santo Agostinho como 'raciocínio ou discurso sobre Deus', na sua essência é una e, como ciência tem características distintas: seu objeto é o Deus uno e único, e estuda o seu sujeito de forma própria a ela própria, ou seja, com o uso da razão iluminada pela revelação" (n. 74). Apesar de os Padres da Igreja conhecerem o termo "teologia" somente na forma singular, pois era o Logos do próprio Deus (n. 75), hoje há uma tendência a usar a palavra no plural: "Fala-se das 'teologias' de diferentes autores, épocas ou culturas, tendo em mente os conceitos característicos, temas significativos e perspectivas específicas dessas 'teologias"' (n. 75). Isso ocorre por vários fatores (n. 76) e é necessária e justificada por causa da "abundância da verdade divina" e da diversidade dos objetos que ele considera e interpreta e a própria diversidade dos questionamentos humanos, refletindo, assim, "a catolicidade da Igreja, que se esforça para proclamar o único Evangelho às pessoas de toda parte e em todos os tipos de circunstâncias" (n. 77). Mas é preciso reconhecer os limites da pluralidade: o pluralismo legítimo se diferencia do relativismo, heterodoxia ou heresia (n. 78). Contudo, deve ser buscada a "unidade entre a pluralidade das teologias" (n. 79). A teologia deve fazer parcerias com a filosofia, com a hermenêutica e com as ciências naturais, econômicas e médicas (n. 81), além de diálogo com as ciências religiosas ou estudos religiosos (n. 83), reconhecendo-lhes a "justa autonomia das outras ciências, a competência profissional e o esforço pelo conhecimento que aí pode ser encontrado" (n. 84). 
A sexta perspectiva é a relação entre a Ciência e a Sabedoria

Como a teologia não é somente uma ciência, mas também uma sabedoria, ela tem um "papel especial a desempenhar na relação entre todo o conhecimento humano e o Mistério de Deus" (n. 86). Por isso, "a contemplação intelectual que resulta do trabalho racional do teólogo é, portanto, uma verdadeira sabedoria" (n. 91), que faz parte da vocação particular que os teólogos receberam para o serviço no corpo de Cristo. "Por esse chamado e pelos dons recebidos, eles têm uma relação particular com o corpo e com todos os seus membros. Vivendo na "comunhão do Espírito Santo" (2Cor 13,13), eles devem procurar, juntamente com todos os irmãos e irmãs, conformar as suas vidas ao mistério da Eucaristia, 'pela qual a Igreja continuamente vive e cresce' (Lumen Gentium, n. 26; Ecclesia de Eucharistia, n. 1). De fato, chamados como são a explicar os mistérios da fé, devem estar particularmente ligados à Eucaristia. (...) Nesse sentido, a teologia pode ser entendida como essencial e profundamente "mística"' (n. 94). Todavia, não se pode esquecer que "o sentido de mistério que caracteriza propriamente a teologia leva a um pronto reconhecimento dos limites do conhecimento teológico, que contrasta com todas as pretensões racionalistas de esgotar o mistério de Deus" (n. 96).

\section{Princípios}

Os princípios estão tratados no segundo capítulo do Documento, intitulado Permanecendo na comunhão da Igreja. O título anuncia um princípio fundamental para o trabalho teológico nos dias atuais. Poderse-ia dizer que, sem a comunhão com a Igreja por parte do teólogo não é possível realizar verdadeira tarefa teológica, pois "a eclesialidade da teologia é um aspecto constitutivo da tarefa teológica, porque a teologia é baseada na fé, e fé, em si, é, ao mesmo tempo, pessoal e eclesial" (n. 20).

Assim, o Documento aponta alguns princípios, que serão expostos a seguir:

Primeiro princípio: O estudo da Escritura como alma da Teologia

Este princípio está de acordo com Dei Verbum 29 e a Optatam Totius 16, reiterado pelo Papa Bento XVI na Verbum Domini 35. É um princípio que já faz parte do consenso da pesquisa e do ensino 
teológicos. Concorre a exegese, enquanto determina "o que Deus quis nos transmitir" (Dei Verbum, n. 12), com três critérios fundamentais, apontados pela Dei Verbum 12, a saber: a unidade da Escritura, o testemunho da Tradição e a analogia da fé. Como afirma o Documento: "É nesse contexto que a exegese busca o sentido literal e se abre para o sentido espiritual ou pleno (sensus plenior) da Escritura" (n. 22). Assim, a Sagrada Escritura fundamenta todas as disciplinas teológicas e a tarefa primária da Teologia "é interpretar a verdade de Deus enquanto verdade salvífica" e, ocupando-se da Palavra de Deus, dá testemunho da Escritura em todo o seu trabalho (n. 23).

\section{Segundo princípio: Fidelidade à Tradição apostólica}

Entende-se por Tradição apostólica a transmissão do estilo integral de vida da comunidade apostólica no Espírito, do qual "a lex orandi (a regra da oração), a lex credendi (a regra da fé) e a lex vivendi (a regra de vida) são seus aspectos essenciais. Paulo se refere à Tradição, na qual ele foi incorporado como um apóstolo, quando fala de "transmitir" aquilo que ele "mesmo recebeu" (ICor 15:1-11, cf. também 1Cor 11,23-26)" (n. 25). "A teologia católica reconhece a autoridade do ensinamento dos concílios ecumênicos, o magistério ordinário e universal dos bispos e o magistério papal" além do "estatuto especial de dogmas, (...) de uma forma que é obrigatória para a Igreja universal, tanto assim que a negação é rejeitada como heresia e tornase um anátema", pois eles "pertencem à Tradição Apostólica viva e sempre atual", apesar "das dificuldades atinentes ao seu trabalho de interpretação" (n. 29). "Na fé católica, a Escritura, a Tradição e o Magistério da Igreja estão inseparavelmente unidos (cf. Dei Verbum, n. 10)" (n. 30). O Vaticano II distingue entre Tradição e as tradições (cf. Dei Verbum, n. 8; Lumen Gentium, nn. 13 e 14; Unitatis Redintegratio, nn. 15 e 17; Ad Gentes, n. 22). Tal distinção "tem sido uma das principais tarefas da teologia católica desde o Vaticano II, e de teologia em geral nas últimas décadas", além de ser "uma tarefa profundamente relacionada à catolicidade da Igreja, e que tem muitas implicações ecumênicas" (n. 31).

\section{Terceiro princípio: Atenção ao sensus fidelium}

A natureza e a localização do sensus fidei ou sensus fidelium deve ser devidamente compreendidas. O sensus fidelium não significa simplesmente a opinião da maioria em um determinado tempo ou 
cultura, nem é apenas uma afirmação secundária em relação com o que vem primeiro ensinado pelo Magistério. O sensus fidelium é o sensus fidei do povo de Deus na sua totalidade, obediente à Palavra de Deus e guiado nos caminhos da fé por seus pastores. Assim, o sensus fidelium é o sentido da fé que está profundamente enraizada no povo de Deus, que recebe, compreende e vive a Palavra de Deus na Igreja (n. 34).

Quarto princípio: Responsável adesão ao magistério eclesiástico

Na teologia católica, o Magistério é um fator fundamental na própria tarefa teológica, já que a teologia recebe o seu objeto a partir de Deus, através da Igreja, cuja fé é autenticamente interpretada pelo 'único Magistério vivo da Igreja', isto é, pelo Papa e os bispos. A fidelidade ao Magistério é necessária para que a teologia possa ser ciência da fé (scientia fidei) e ter uma função eclesial. Uma correta metodologia teológica requer, portanto, uma compreensão adequada da natureza e da autoridade do Magistério em seus diversos níveis e das relações que corretamente existem entre o Magistério eclesiástico e a teologia. Bispos e teólogos têm vocações distintas, e devem respeitar as respectivas competências, para evitar que o Magistério reduza a teologia a uma ciência meramente repetitiva ou os teólogos tenham a pretensão de substituir o ofício de ensino dos pastores da Igreja (n. 37).

A compreensão da Igreja como comunhão é um "bom quadro de referência para se estabelecer uma relação frutífera entre teologia e Magistério" (n. 38). A interpretação "autêntica da fé" é feita pelo Magistério (n. 40) e os teólogos são chamados a colaborar, a obedecer e avaliar de forma crítica, construtiva (n. 41), com liberdade, que "deriva de uma verdadeira responsabilidade científica de teólogos" (Tese 8 do Documento: Teses da relação entre o Magistério eclesiástico e a Teologia).

Quinto princípio: Na companhia dos teólogos

O ministério dos teólogos é pessoal, comunitário e colegial, isto é, "ele é exercido na e para a Igreja como um todo, e é vivido em solidariedade com aqueles que têm a mesma vocação" (n. 45). Isso acontece nas faculdades e escolas teológicas, nas sociedades e associações teológicas, na colaboração em projetos de pesquisa e publicações, nos mútuos questionamentos e correções (nn. 45-46 
e 48). Tal colaboração inclui os teólogos leigos (n. 47). Além disso, os teólogos "precisam e merecem o apoio orante de toda a comunidade eclesial", e de "uma atenta adesão aos critérios fundamentais da teologia católica", além de "reconhecer a provisoriedade intrínseca de seus esforços, e oferecer seu trabalho para a análise e avaliação de toda a Igreja" (n. 47). "O diálogo ecumênico e a pesquisa constituem-se em um campo privilegiado e potencialmente produtivo entre teólogos católicos e de outras tradições cristãs" (n. 49).

\section{Sexto princípio: Em diálogo com o mundo}

A teologia tem uma competência específica e uma responsabilidade no perscrutar os sinais dos tempos (signa temporum perscrutandi). "Através de um diálogo constante com as correntes sociais, religiosas e culturais do tempo, e com abertura a outras ciências (...), a teologia pode ajudar os fiéis e o Magistério a ver a importância das evoluções, acontecimentos e tendências da história humana, e a discernir e interpretar as formas através das quais o Espírito possa estar falando para a Igreja e para o mundo" (n. 53). Tal diálogo beneficia tanto a Igreja quanto a cultura humana (n. 56).

\section{Critérios}

Das perspectivas e dos princípios brotam os critérios para a Teologia Católica, como se fossem consequências do que foi enunciando anteriormente, pois perpassam todo o documento. Eles são elencados a seguir, de acordo com o texto do Documento:

\section{1º critério: Primazia da Palavra de Deus}

Um critério da teologia católica é o reconhecimento da primazia da Palavra de Deus. Deus fala "muitas vezes e de modos diversos": na criação, através dos profetas e sábios, por meio das Sagradas Escrituras e, de forma definitiva, através da vida, morte e ressurreição de Jesus Cristo, o Verbo feito carne (cf. $H b$ 1,1-2) (n. 9).

\section{2 critério: A fé da Igreja como fonte, contexto e forma}

Um critério da teologia católica é que ela tem a fé da Igreja como fonte, contexto e norma. A teologia mantém a fides qua e a fides quae unidas. Ela expõe o ensinamento dos apóstolos, a Boa Nova sobre Jesus Cristo, "segundo as Escrituras" (1Cor 15,3-4), como regra e estímulo da fé da Igreja (n. 15). 
3ㅜ critério: Como ciência da fé, a "fé busca compreender"

Um critério da teologia católica é que, precisamente como a ciência da fé, a "fé busca compreender" (fides quaerens intellectum), ela tem uma dimensão racional. A teologia se esforça para compreender o que a Igreja crê, e que pode ser conhecido sub specie Dei. Como scientia Dei, a teologia procura compreender de forma racional e sistemática a verdade salvífica de Deus (n. 19).

4º critério: Atingir o testemunho canônico da Escritura

Um critério da teologia católica é que ela deve atingir constantemente o testemunho canônico da Escritura e deve promover que tal testemunho esteja ancorado em toda a doutrina e prática da Igreja, uma vez que "toda a pregação da Igreja, como a própria religião cristã, seja alimentada e regida pela Sagrada Escritura". A teologia deve esforçar-se para abrir amplamente a Escritura aos fiéis cristãos, de modo que estes possam entrar em contato com a Palavra viva de Deus (cf. $H b$ 4,12) (n. 24).

\section{5ㅜ critério: Fidelidade à Tradição Apostólica}

A fidelidade à Tradição Apostólica é um critério da teologia católica. Essa fidelidade requer uma recepção ativa e com discernimento dos vários testemunhos e expressões da Tradição Apostólica até agora em curso. Isso implica o estudo da Sagrada Escritura, da liturgia e dos escritos dos Padres e Doutores da Igreja, além da atenção ao ensinamento do Magistério (n. 32).

6o critério: Atenção ao sensus fidelium

Atenção ao sensus fidelium é um critério para a teologia católica. A teologia deve esforçar-se para descobrir e articular com precisão em que os fiéis católicos realmente acreditam. Ela deve falar a verdade no amor, para que os fiéis possam amadurecer na fé, e não serem "joguetes das ondas e agitados por todo vento de doutrina $(E f 4,14-15) "$ (n. 36).

7º critério: Adesão responsável ao Magistério eclesiástico em suas várias graduações

Dar adesão responsável ao Magistério em suas várias gradações é um critério da teologia católica. Os teólogos católicos devem reconhecer a competência dos bispos e, especialmente, do colégio dos bispos com o chefe, o Papa, para dar uma interpretação autêntica da Palavra de Deus transmitida na Escritura e na Tradição (n. 44). 
$\boldsymbol{8}^{\text {o }}$ critério: Exercido em colaboração profissional na oração e na caridade

Um critério da teologia católica é que ela deve ser exercida em colaboração profissional, na oração e na caridade, com toda a comunidade de teólogos católicos na comunhão da Igreja, em espírito de estima e apoio mútuos, atenta tanto às necessidades e aos comentários dos fiéis quanto à orientação dos pastores da Igreja (n. 50).

\section{9o critério: Em constante diálogo com o mundo}

Um critério da teologia católica é que ela deve estar em constante diálogo com o mundo. Ela deve ajudar a Igreja a ler os sinais dos tempos, iluminados pela luz que vem da revelação divina, e nisso fazer ganhar em sua vida e missão (n. 58).

$10^{\circ}$ critério: Esforço para fazer uma apresentação científica e racional das verdades da fé cristã

Um critério da teologia católica é que ela deve se esforçar para fazer uma apresentação científica e racional das verdades da fé cristã. Para isso, necessita fazer uso da razão e deve reconhecer a forte relação entre a fé e a razão, em primeiro lugar razão filosófica, de modo a superar tanto o fideísmo quanto o racionalismo" (n. 73).

$11^{\text {o }}$ critério: Unidade da teologia na pluralidade de questões e métodos

Um critério da teologia católica é que ele tenta integrar uma pluralidade de questões e métodos para o projeto unificado do intellectus fidei, e insiste na unidade da verdade e, portanto, sobre a unidade fundamental da própria teologia. A teologia católica reconhece os métodos próprios de outras ciências e os utiliza criticamente em sua própria pesquisa. Ela não se isola da crítica e está aberta ao diálogo científico (n. 85).

\section{$12^{\circ}$ critério: Alegrar-se com a sabedoria de Deus}

Um critério da teologia católica é que ela deve procurar e alegrar-se com a sabedoria de Deus, que é loucura para o mundo (cf. 1Cor 1,18-25; 1Cor 2,6-16). A teologia católica deve enraizar-se na grande tradição sapiencial da Bíblia, conectar-se com as tradições do cristianismo do Oriente e do Ocidente, e procurar estabelecer uma ponte com todas as tradições de sabedoria. 
Na busca da verdadeira sabedoria no estudo do Mistério de Deus, a teologia reconhece a prioridade absoluta de Deus; pretende não possuir, mas ser possuída por Deus. Ela deve, portanto, estar atenta ao que o Espírito diz às Igrejas, por meio do "conhecimento dos santos". A teologia comporta um esforço para a santidade e uma consciência cada vez mais profunda da transcendência do mistério de Deus (n. 99).

Recebido: 16/06/2014

Avaliado: 20/06/2014 